\title{
Minorías y democracia
}

\author{
P. Juan Bottasso, sdb ${ }^{*}$
}

\section{El problema}

ue el Ecuador sea un país multiétnico y pluricultural es algo que se ha repetido hasta la saciedad; se trata además de un hecho tan evidente que no son necesarios muchos argumentos demostrativos. Por otro lado, son muy pocos los países de este mundo que no poseen una gran variedad de características culturales. Los que presentan cierta homogeneidad son aquellos que han podido disponer de un largo período para fusionar los elementos diferentes, a través de una lenta labor de mestizaje, o se han entregado a una violenta operación de "limpieza étnica", como ha sucedido recientemente en ciertas áreas del planeta. Los hay también aunque no muchos, los que han sabido conciliar diversidad y unidad. Pero, decir que el Ecuador es un mosaico de culturas y etnias, es decir mucho o casi nada, al mismo tiempo. Las que cuentan son las relaciones entre los grupos, relaciones que nunca son simétricas. Dentro de la variedad puede haber grupos dominantes y grupos marginados, algunos con posibilidad de decisión y otros sin el mínimo peso político, algunos numerosísimos y otros reducidos a pocos centenares de personas.

No es solo cuestión de admitir la variedad, sino de entender qué peso y qué significado tiene.

* Docente de la Carrera de Antropología de la UPS Quito. 
Para hacer un ejemplo: en algunos países del surdeste asiático existen colonias chinas, como en Singapur, Malasia, Indonesia y Filipinas. Son enclaves numéricamente muy reducidos, pero condicionan toda la vida del país, porque tienen una enorme influencia económica. También en el Ecuador existen minorías llegadas al país durante el siglo $\mathrm{XX}$, que son poco numerosas, pero con un notable peso específico, como los sirio-libaneses y los judíos. Con todo, para no ampliar excesivamente el tema de esta reflexión, me limitaré a hablar de las minorías que viven en el país desde tiempos ancestrales, anteriores a la llegada de los europeos. Ellas han pasado por un proceso de coloniaje que les ha quitado la posibilidad de expresarse, aun cuando se les ha informado que ahora hacen parte de un estado democrático. Sabemos muy bien que, cuando la democracia se reduce a un conteo de votos cada cierto tiempo, es una pobre cosa y no se puede decir que dé voz a los pueblos que tienen una larga historia, un idioma, creencias y estructuras propias, pero son poco numerosos. Si de veras se quiere construir una sociedad en la que cada ciudadano participe, hay que explorar otros caminos, diferentes a los que hemos recorrido hasta hoy.

\section{Un poco de historia}

El Ecuador fue uno de los países de América al que, proporcionalmente, acudió menos población europea. Su enclaustramiento, por lo menos hasta el corte del istmo de Panamá, su geografía que volvía problemáticos los desplazamientos, la intranquilidad política que coincidió con el período en que la población europea en exceso iba poblando grandes espacios de América Latina, fueron factores que frenaron la inmigración. Entre 1778 y 1881, es decir, poco antes de la independencia, el Visitador nombrado por Madrid, Juan José de Villalengua, emprendió un censo de la 
población de la Real Audiencia de Quito (que tenía entonces una superficie bastante superior a la del Ecuador actual). Se trataba de una iniciativa que hacía parte del plan de los Borbones para actualizar la reforma tributaria. Según este censo los habitantes eran aproximadamente 439000 , de los cuales el $63 \%$ eran indígenas, el $11 \%$ los llamados castas y negros. El 26\%, es decir 113000 personas, eran peninsulares, criollos y mestizos blanqueados.

Como se puede ver, el porcentaje de los mestizos (en parte censados con los blancos y en parte con los negros) era todavía bastante bajo, porque los dos bloques poblacionales, -blancos e indios- constituían dos entidades muy distanciadas. A lo largo del siglo XIX el fenómeno del mestizaje no dejó de crecer, hasta llegar a la situación actual, en la que la gran mayoría de los ecuatorianos se considera mestizo.

En el censo de 2001 , menos del $7 \%$ de la población declaró considerarse indígena. Se puede discutir sobre el significado y el alcance de este porcentaje, pero está fuera de duda que un gran número de individuos, de descendencia inequívocamente indígena, hoy prefieren ser considerados mestizos. Un vasco o un catalán podrían tener diferentes conceptos sobre su manera de pertenecer a España, pero es casi imposible que oculten su pertenencia étnicocultural: tienden más bien a exhibirla con orgullo. Si un alto número de indígenas ecuatorianos prefiere no ser identificado como tal, es porque, por algún motivo, ese orgullo ha desaparecido. Es curioso que, a medida que la población indígena ha ido perdiendo consistencia numérica frente a la masa de la población, ha aumentado, por lo menos en ciertos grupos, la conciencia de identidad étnica y la reivindicación de los derechos ciudadanos y políticos.

Mucho tuvo que ver con este fenómeno el cambio que se ha dado en el escenario mundial: independencia de Asia y África, descolonización, luchas antiimperialistas; 
pero intervinieron también factores locales de diferente índole. Nombro algunos: por ejemplo, las luchas llevadas a cabo por la Federación Ecuatoriana de Indios (FEI), brazo derecho del Partido Comunista ecuatoriano, especialmente en las zonas de Zumbahua y Cayambe. Allí se movilizaron los trabajadores de las haciendas de la Asistencia Pública que, antes de la Revolución liberal, habían pertenecido a las órdenes religiosas. Estas reivindicaciones desembocaron en los años 60 en la Reforma Agraria, que convirtió las haciendas en cooperativas y asignó las tierras a los indígenas.

Desde la presidencia de Galo Plaza se intensificó la presencia de los evangélicos en el Ecuador. Su afán por hacer conocer la Biblia en todos los idiomas los llevó a contactar a todos los pueblos indígenas. El Instituto Lingüístico de Verano se preocupó por estudiar los idiomas de los diferentes grupos e introdujo la educación bilingüe, siendo así pionero en este campo, por lo menos en los tiempos modernos. Este hecho ayudó a crear conciencia, porque varios idiomas, por primera vez, llegaron a escribirse, lo que aumentó el aprecio por ellos.

En enero de 1964 se fundó en Sucúa (Morona Santiago) la Federación de Centro Shuar, que tuvo un influjo indudable en la creación de las demás organizaciones indígenas. En los últimos 30 años ha ido cambiando radicalmente tanto el concepto que los indígenas tenían de sí mismos, como la percepción de la opinión pública con respecto a ellos.

Siglos de marginación y menosprecio habían logrado que interiorizaran una visión negativa de sus propias posibilidades ("naturales no más somos"). En la segunda mitad del siglo XX empezó a darse el cambio. Algunas causas ya las he enumerado, otras también tuvieron su peso: la escolarización progresiva, aunque de baja calidad, las migraciones temporales a la ciudad, la concesión del derecho de voto a 
los analfabetos. Un impacto nada despreciable tuvo, sin duda, la figura y la práctica del obispo Leonidas Proaño. El panorama comenzó a moverse y los cambios se hicieron siempre más visibles: exigencia de mayor respeto (por ejemplo en el transporte), reclamo de espacios de expresión en las instancias del poder local, protestas apoyadas en paros, pedido de reconocimiento de su idioma en el ámbito público. La aprobación de la educación bilingüe intercultural fue un paso notable, aunque con efectos contradictorios. Un hito importante, también a nivel emblemático, fue el levantamiento de 1990, que permitió a los indígenas medir su fuerza política, desde que se dieron cuenta que podían paralizar el país, con el bloqueo de las carreteras.

El derrocamiento del presidente Mahuad fue una demostración de poder más aparente que real, porque se vio claro que, detrás de los ponchos, la fuerza real descansaba en las armas de los coroneles. Esto dio lugar a una situación bastante ambigua. Cuando el coronel Lucio Gutiérrez llegó al poder a través del voto, los indígenas manifestaron el convencimiento de haber sido sus principales electores y exigieron una cuota consistente de poder. "No colaboramos con el Gobierno, dijo en esos días el líder Miguel Lluco, sino que somos gobierno". Después de pocos meses el coronel los marginó, sin que se produjeran reacciones de consideración. Pero no es mi intención recorrer los hechos y los acontecimientos de un proceso sobre el cual se ha escrito y comentado muchísimo. Mi propósito es el de, simplemente, aclarar algunos conceptos cuyo sentido se utiliza a veces de manera ambigua y hasta contradictoria.

\section{Indígenas y Estado: una relación complicada}

Durante la colonia los indígenas nunca fueron considerados ciudadanos a título pleno. A decir verdad, la pala- 
bra "ciudadano" se acuñó solo con la Revolución Francesa, pero, si se quiere decir lo mismo con otra expresión, hay que afirmar que nunca fueron considerados personas adultas. El Código de Indias contenía una infinidad de leyes que tutelaban a los indígenas: ningún imperio, a lo largo de la historia, había legislado tanto a favor de los vencidos. Pero el hecho es que estos fueron considerados permanentemente como menores, necesitados de tutores, incapaces de decisiones responsables. Nunca hubo la preocupación por integrarlos a la sociedad blanco-mestiza; al contrario, se favoreció la separación, tanto a través de la barrera idiomática, como por medio de la vestimenta y la negación de la educación.

La independencia no solo no los favoreció, sino que empeoró su situación. A cuenta de la "égalité", se les privó de las tutelas jurídicas de los tiempos coloniales $y$, en muchos casos, se cercenaron sus tierras comunales, para asignarlas a los veteranos de las guerras de independencia. Es en la segunda mitad del siglo XIX que las cosas empezaron a cambiar. Las repúblicas latinoamericanas, salidas de la convulsión que siguió a las luchas de emancipación y lograda una relativa estabilidad interna, empezaron a apuntar decididamente hacia la modernización. La presencia de grupos autóctonos, considerados primitivos -especialmente los habitantes de las selvas- las incomodaba, también, por la imagen que proyectaban hacia el exterior. No faltaron quienes, como en 1907 el Dr. Hermann von Shering, director del Museo Paulista en Brasil, propusieron la solución radical de exterminar las tribus selvícolas por ser un obstáculo para el progreso, en cuanto atacaban a los trabajadores que tendían la línea del telégrafo hacia el interior. A los "progresistas" no se les ocurría sospechar que los invasores fueran ellos y no los indios, porque las palabras que campean en la bandera brasileña "Ordem e Progresso" eran una consigna sagrada e indiscutible. 
Pocos años antes, Argentina había llevado a cabo la "Expedición del Decreto" con el general Roca, verdadera guerra contra los Mapuches, culpable de frenar la expansión agropecuaria hacia Patagonia. Chile empujaba su frontera hacia el sur guerreando contra los Araucanos. Así que, por aquellas latitudes, el exterminio de los indios no se dio en tiempos de la colonia, sino de la república. Pero no faltaron propuestas más humanitarias.

La aplicación del darwinismo biológico a las ciencias sociales hizo que muchos consideraran las diferencias culturales en perspectiva evolucionista. De acuerdo a este enfoque, no existen razas inferiores, sino solo grupos humanos que, por circunstancias históricas, climáticas o de otra índole, han quedado rezagadas. Se trataría simplemente de elevarlas poco a poco al nivel de los grupos avanzados, a través de la educación; todos los seres humanos son susceptibles de civilizarse, si se les brinda la oportunidad. Esta visión fue ganando a los sectores más abiertos de la sociedad y desencadenó una verdadera fiebre "civilizadora".

En los escudos de armas de países, provincias, planteles educativos, sindicatos y sociedades filantrópicas fue enarbolada la antorcha, símbolo de la ciencia y se emprendió una cruzada contra el oscurantismo. A pesar de que este se lo identificara a menudo con la religión y el clericalismo, para "agregar a la nación y a la civilización las tribus bárbaras de Oriente", los gobiernos llamaron a congregaciones y órdenes religiosas.

\section{Propuestas contradictorias}

\subsection{El asimilacionismo}

Ya antes de la Revolución Liberal, el programa de los Gobiernos apuntaba sin titubeos a la asimilación. Los indios 
tienen un espacio dentro del país, con tal que acepten entrar en el cauce del progreso: que vistan y hablen como la gente, vayan a la escuela, hagan la conscripción, produzcan y consuman como todo buen ecuatoriano. En otras palabras: que dejen de ser indios y se conviertan en ciudadanos genéricos.

El Ministerio de Educación fue el gran instrumento para la actuación de este programa, pero no fue el único. Como los beneficios de la escuela habían alcanzado solo una parte de la población indígena, el gobierno de Osvaldo Hurtado extendió el derecho de voto a los analfabetos. La medida fue muy criticada por quienes consideraban imprudente admitir al juego democrático a personas que podrían ser fácilmente manipuladas, pero constituyó un hito fundamental. Los políticos comenzaron a visitar las áreas indígenas, a hacer promesas, a realizar una que otra obra, a valorar a los líderes locales.

\subsection{La visión clasista}

Como ya se dijo, alrededor de la mitad del siglo XX, los partidos de izquierda se preocuparon por organizar $y$ movilizar a los indios, pero dentro de un esquema clasista. El marxismo trata las diferencias culturales como algo romántico que, en lugar de compactar a las masas populares, las fragmenta. Lo importante es en cambio la unión de los pobres en su lucha contra los explotadores. Los indígenas pertenecen masivamente al mundo de los pobres, su ubicación natural debe ser al lado de los proletarios. El ejemplo clásico para ilustrar esta posición fue la incapacidad que manifestó Tomás Borges para entender los planteamientos de los Miskitos en Nicaragua, cuando el Sandinismo estuvo en el poder.

A pesar de las apariencias, este camino conduce a los mismos resultados que la propuesta asimilacionista; las 
características específicas de cada pueblo desaparecen, para dar lugar a una total homogeneización, dentro del proletariado. Así, los indios fueron convirtiéndose poco a poco en campesinos y muchos de sus líderes empezaron a viajar a Cuba y a la Unión Soviética, para ser adoctrinados, de acuerdo al nuevo catecismo. Cuando cae el muro de Berlín y entra en coma profundo el socialismo real con sus conexiones internacionales, muchos activistas e ideólogos de izquierda, que se resisten a aceptar la nueva realidad, se refugian en las organizaciones indígenas y se convierten en padres espirituales de sus directivas.

La religiosidad, en cuanto fenómeno superestructural de larga duración, es vista como un freno para el cambio. A pesar de esto, no son pocos los católicos, autodefinidos comprometidos y progresistas, que simpatizan por esta corriente de pensamiento, la cual, a pesar de su aspecto científico, es muy vulnerable desde el punto de vista antropológico. De hecho se ha revelado incapaz de calar en el corazón de las masas indígenas.

\subsection{La propuesta étnica}

Es especialmente en Bolivia, el país sudamericano con más alto porcentaje de población indígena, que se va fomentando otra alternativa. Los pueblos indígenas, más que como parte de una clase social, son vistos como pueblos o naciones que tienen derecho a conservar su identidad y autonomía. Es un planteamiento que todavía hoy mantiene en zozobra el escenario político de Bolivia, a pesar del evidente peligro de convertirse en algo romántico o folklórico. ¿Cómo conservar estas islas culturales, sin cuestionar el mar que las rodea, el de un capitalismo dependiente, deshumanizante y destructor de los más débiles?

Este discurso no se aclimató en tierras ecuatorianas, si se exceptúan ciertas posiciones de unas franjas maxima- 
listas de la CONAIE. La propuesta de convertir al Ecuador en un país plurinacional van un poco en esta línea. Las organizaciones que simpatizan por ella generalmente están asentadas en áreas petrolíferas, donde la perspectiva de disponer del subsuelo puede alimentar fuertes tentaciones.

\section{Puntulizaciones indispensables}

La situación no ha dejado de evolucionar en la última década, bajo el empuje de los cambios a nivel mundial. Pero antes que nada es indispensable aclarar el alcance de ciertos términos que se utilizan con frecuencia, pero con significados diferentes.

\subsection{Tolerancia y pluralismo}

Hasta las terribles guerras de religión que ensangrentaron la Europa de la Reforma y de la Contrareforma, se creía que el secreto de la fuerza de un estado residiera en la unanimidad de pensamiento de los súbditos: la opinión diferente a la oficial se la consideraba inaceptable, por subversiva. Cuando España logró la unificación política -primer país europeo en alcanzarla- se apresuró a expulsar a moros y judíos. Si querían quedarse debían hacerse católicos, es decir, abrazar la ideología oficial. Muchos no tuvieron el valor de dejarlo todo y aceptaron la propuesta, pero se los siguió mirando con desconfianza, cuando no fue con la abierta sospecha de que estuvieron fingiendo. La Inquisición en ningún momento dejó de vigilarlos.

En el siglo XVII comenzó a abrirse campo una visión que conduciría más tarde a la construcción de la democracia liberal. Para el politólogo Giovanni Sartori, es en Inglaterra y Francia, no en la Grecia de Pericles, que nace la democracia moderna. Según este enfoque el disentir (la oposición) no solo no debilita, sino que enriquece. Aceptar 
lo diferente como una riqueza permite construir una sociedad pluralista y tolerante. Estas dos palabras están íntimamente entrelazadas, pero no se las puede utilizar como sinónimos intercambiables. Siempre según Sartori, el verdadero pluralismo debería presuponer la tolerancia sin, por ello, identificarse con la misma. La tolerancia respeta los valores ajenos mientras que el pluralismo exige respeto para los propios.

Un ejemplo esclarecedor es el de los puritanos, tanto ingleses como norteamericanos. Para ellos democracia y libertad eran palabras despreciables: la libertad de conciencia y de opinión que reivindicaban era la de su propia conciencia, no la de los demás. En este sentido, pedían pluralismo, pero no eran tolerantes, como no eran tales muchos imperios de la antigüedad que abarcaban pueblos supremamente diferentes, pero eran absolutistas y tiranos. Tampoco es del todo tolerante la India de nuestros días, muy variada en sus expresiones culturales, pero renuente en conceder todos los derechos a ciertas minorías.

5.2. Queremos ser iguales, pero tenemos derecho a ser diferentes

Estas dos exigencias suenan como contradictorias, pero lo son solo en apariencia. Se podría decir que, históricamente, son dos momentos de un mismo proceso que no se dio solamente al interior de las luchas indígenas, sino también de otras, como por ejemplo, en el movimiento feminista y negro. Al tomar conciencia de una larga marginación, es comprensible que la primera reacción consista en reivindicar la igualdad de derechos, de dignidad, de oportunidades. Una vez alcanzado este primer objetivo, se cae en la cuenta de que la igualdad jurídica puede llevar fácilmente a la homologación total, con la consecuente pérdida de la propia identidad. A este punto no se rechazan los logros conse- 
guidos, sino que, partiendo de ellos, se reivindica un espacio para la propia especificidad. No hay duda que conciliar las dos exigencias no es nada fácil, especialmente, si se asumen posiciones radicales.

Lo que en estos últimos tiempos puso de relieve la dificultad para administrar este dualismo han sido las migraciones. Desplazamientos de grupos humanos, los hubo desde la prehistoria. Los siglos XIX y XX fueron testigos de enormes migraciones entre continentes, pero, hasta cierto punto, las dimensiones del fenómeno permitieron que los recién llegados fueran absorbidos por el ambiente receptor. Pensemos en Argentina, Uruguay y Estados Unidos. Son países hechos de migrantes, pero allí nunca se dejó de tener como único idioma oficial el castellano o el inglés. Las cosas cambiaron en los últimos años con consecuencias profundas, también en países que no vivieron un fenómeno de características parecidas. Más adelante se considerarán algunos ejemplos de convivencia entre diferentes, con sus logros y fracasos.

\subsection{El concepto de nación}

En las siglas de las organizaciones indígenas (CONAIE, CONFENAIE,...) aparece a menudo la letra "N", que está por nación o nacionalidad. Este es otro término que necesita ser aclarado, porque un uso ambiguo puede dar lugar a grandes confusiones. No me propongo ahondar en la exploración del significado y alcance del término, sino simplemente recordar algunas acepciones que asumió a lo largo de la historia. Ya en tiempos coloniales se llamaban naciones las etnias autóctonas no evangelizadas, en consonancia con el sentido que la Biblia atribuía al término. Pero remontémonos más atrás: durante la edad media prevalecían los universalismos, el imperial y el papal. Al tratarse de unidades demasiado amplias, poco a poco fueron delineán- 
dose las que serían después las comunidades nacionales. España fue la primera en alcanzar la conciencia de unidad, a través de la larga lucha contra los moros. El enfrentamiento secular contra una realidad cultural diferente reforzó la conciencia de la propia identidad. Otros países siguieron a España, como Francia. Lo que rompió definitivamente la homogeneidad universalística de la Europa cristiana fue la Reforma Protestante. La traducción de la Sagrada Escritura a los idiomas vernáculos tuvo repercusiones enormes.

Intervinieron también otros elementos: los descubrimientos geográficos que acentuaron la idea de la diversidad de los pueblos; el fortalecimiento de los Estados centralizados; la preocupación de legitimarlos, investigando sus raíces históricas. De esta manera fue formándose el concepto de nación, percibida como una colectividad que tiene en común historia, lengua, costumbres: algo esencialmente cultural, sin peso político efectivo. Es con J. J. Rousseau y la Revolución francesa que la "nación", luchando contra los privilegios del rey y de la aristocracia, se afirma como sujeto político, que alcanza a todos los ciudadanos. La nación, entendida como comunidad de individuos que deciden libremente asociarse, llega a ser artífice de una nueva legitimidad política, alternativa al poder absoluto del rey.

El romanticismo hace del concepto de nación un poderoso instrumento de integración cultural y mítico-simbólica, para sociedades en proceso de modernización que mina antiguos vínculos de pertenencia. En Europa son típicos los casos de Alemania e Italia. En Polonia fermentan movimientos de independencia y unificación que fraguarán solamente después de la Primera Guerra Mundial. En América Latina se fracciona el imperio ibérico, dando lugar a decenas de países, cada uno de los cuales subraya su diversidad cultural e histórica frente a los otros, redescubriendo un pasado a veces mitificado. Pensemos, por ejemplo, en la utilización instrumental que hizo el Ecuador de la 
idea del Reino de Quito. Los escudos de armas, los himnos nacionales, la retórica de los discursos fiscales y de los libros de texto, son un testimonio palpable de esta realidad.

Mientras tanto en ciertas áreas, especialmente en Alemania, a fines del siglo XIX y en las primeras décadas del siguiente, se abre paso una visión absolutista de nación. Ella exalta los vínculos culturales pero, sobre ellos, afirma la primacía de lo étnico. La pertenencia se define en base a la sangre, aun por encima de la voluntad de las personas. De aquí a elevar el racismo a política de estado hay solo un paso. La nación es exaltada sobre todos los valores, aun sobre la libertad individual. Esta evolución negativa del nacionalismo produjo consecuencias apocalípticas: dos guerras mundiales en tres décadas, con decenas de millones de muertos. La reacción a estos excesos ha conducido a la situación en que vivimos. No son pocos los que consideran los estados nacionales bajo una luz negativa: conservan fronteras anacrónicas y justifican estructuras militaristas que succionan los presupuestos y enturbian las aguas de la política, con continuas intromisiones. Los que así ven las cosas, proponen articular unidades mucho más amplias, que ahorren enfrentamientos y faciliten los intercambios.

En el campo económico este proceso ya se está dando. Se trataría de pasar al campo político como, trabajosamente, intenta hacer Europa. Como puede verse, el concepto de nación ha ido asumiendo significados bastante diferentes. Cuando los indígenas reivindican para sus pueblos el uso de este término, deben especificar cuál es su alcance. Quedaría por nombrarse a un término que reviste una importancia capital: el territorio, considerado el soporte material de la nación. Pero, al hablar de territorio, se piensa inmediatamente en el subsuelo y sus posibles recursos: ningún tema es tan explosivo como este. Sin olvidar que, cuando las migraciones han ido esparciendo los diferentes grupos étnicos en casi todo el territorio nacional o los han agru- 
pado en las grandes urbes, es prácticamente imposible discernir territorios y establecer fronteras.

Este panorama tan complejo lleva a plantear el problema de la relación entre Estado y Nación. A primera vista los conceptos son claros, pero se complican cuando se analizan las realidades históricas concretas. Las crónicas de todos los días nos informan sobre las dificultades que deben sortear los estados compuestos por naciones diferentes, como, por ejemplo Rusia, Afganistán o el mismo Irak. El recuerdo de las tragedias que generó la explosión de un estado plurinacional como Yugoslavia queda imborrable e induce a no ser ingenuos al momento de hacer propuestas.

\section{Algunos modelos de convivencia}

Aun al precio de alargarme un momento del escenario ecuatoriano y latinoamericano creo oportuno describir unos casos que están influenciando la evolución de las ideas a nivel mundial y pueden sugerir reflexiones útiles para el Ecuador.

\subsection{Francia}

De acuerdo a una larga tradición y siguiendo el recorrido ensayado desde la época colonial, Francia ha obrado siempre según los principios de la integración. La meta es que todos, autóctonos e inmigrantes, lleguen a ser ciudadanos, enmarcados en el modelo de los valores inscritos en la constitución: paridad de derechos, laicidad, igualdad. Pero, después de treinta años de inversiones colosales, leyes y debates culturales, el modelo está evidenciando grandes fisuras. Las masas musulmanas no se han integrado, la desocupación en su interior es de tres a cuatro veces mayor que entre los franceses de sangre, la xenofobia va en 
aumento. Los problemas que ha suscitado la prohibición del velo en las escuelas públicas para las chicas musulmanas (muchas de ellas inmigrantes de tercera y cuarta generación) ha dado publicidad al malestar.

La existencia de minorías no integradas, en cuyo interior tienen fácil cabida grupos extremistas y radicales, preocupa seriamente a las autoridades, porque pone en riesgo los fundamentos de la República. A nivel popular, el miedo al terrorismo resulta ser el problema más grave. En Francia el debate está abierto. Por lo pronto, lo que todo esto nos enseña es que la integración es muy problemática.

\subsection{Inglaterra}

El modelo inglés es tan diferente del francés como lo han sido los estilos de colonización de ambos países. A diferencia de Francia que hizo de las prefecturas, tanto en la madre patria como en los territorios de ultramar, un instrumento centralizado y rígido de administración, Inglaterra practicó la administración indirecta, que dejaba amplios espacios de autonomía a las organizaciones y estilos de vida locales. Lo que se dio en llamar pluralismo. De vez en cuando, el estallido de ciertas cinturas urbanas, pobladas por inmigrantes, había sonado como una alarma, pero fueron los atentados de julio de 2005 los que pusieron en alerta roja a la opinión pública y el gobierno. Individuos de origen no inglés, pero aparentemente integrado y respetuoso del orden constituido, nacidos y educados en la isla, resultaron ser unos terroristas que se habían preparado con minuciosidad para atacar a las instituciones y la paz ciudadana. $Y$ no se trataba de locos aislados, sino de personas que gozaban de la simpatía y el apoyo de círculos bastante consistentes. El caso inglés plantea muchas preguntas. La principal es esta: ¿cuáles son los límites del pluralismo? ¿Hasta dónde se lo puede aceptar sin poner en riesgo la sobrevivencia misma del estado? 


\subsection{Holanda}

La patria de las libertades, el laboratorio más avanzado del multiculturalismo, está en crisis. Hasta tiempos recientes allá prevalecía el consentimiento de que fuera suficiente dejar absoluta libertad a todas las etnias y todas las religiones, en nombre del relativismo cultural, para que la libertad llegara a ser un patrimonio común. Pero el asesinato de Theo van Gogh, nieto del célebre pintor, reveló una realidad muy preocupante. La aparente tolerancia no era otra cosa que indiferencia de los unos hacia los otros. Jaffe Vink, editorialista de un periódico muy difundido, analiza las causas del fracaso. "Creíamos vivir en una nación pacífica, en cambio la criminalidad ha aumentado al $100 \%$. No hemos visto la brecha enorme que se estaba abriendo. Pensábamos que, aprendiendo nuestra cultura ellos dejarían algo de la suya. Hemos sido poco claros con respecto a nuestra cultura y a sus deberes. No hemos sido severos, hemos tenido demasiada confianza en nosotros mismos... El multiculturalismo ha muerto, la sociedad multicultural no existe... El melting pol no es nuestro caso". Es un ambiente diferente del nuestro, pero ¿del todo diferente? Demos una mirada a las pandillas que aterrorizan también las ciudades del Ecuador y preguntémonos sobre el origen de sus integrantes.

\subsection{Estados Unidos}

A costa de alargar demasiado la lista de "modelos actuales de convivencia", no podemos no dar una mirada al país del Norte, objeto de amor y odio de parte de los latinoamericanos. Son pocos entre ellos los que no tienen allá un pariente, más o menos cercano. Samuel P. Hungtington, autor del célebre "Choque de las civilizaciones" ha publicado últimamente "¿Quiénes somos? Es un prolongado grito de alarma sobre el peligro de desintegración del país. 
Resumiendo en extremo su pensamiento, se lo podrá sintetizar así: Estados Unidos es un país de inmigrantes que, alrededor de un núcleo cultural, ha logrado integrar a millones de individuos llegados desde todas las latitudes. Ese núcleo se lo puede resumir en el llamado "credo americano": fuerte religiosidad, estado laico, respeto de las leyes, culto del trabajo, pago de los impuestos. La aceptación de estos principios ha permitido la creación de un país fuertemente cohesionado. La Constitución sigue siendo la misma, después de más de 200 años, el inglés ha servido de instrumento unificante, la ética protestante de principio inspirador. Pero este bloque se puede resquebrajar: grandes masas de hispanos traspasan las fronteras, formando enclaves que no se asimilan. Siguen con sus costumbres, sus fiestas, el uso del español. Nueva York es una ciudad medio hispana, Miami ni hablar y California va por buen camino. Hungtington se pregunta si se conservará unitario un país en el que se incrusta un archipiélago de islas con otras costumbres y otra lengua.

Las reacciones a sus planteamientos fueron muy fuertes, especialmente de parte de los mexicanos, que le acusaron de ver solo peligros y no ventajas. Pero el hecho que haya despertado tanta polémica demuestra que ha tocado un nervio descubierto y que sus observaciones se pueden discutir, pero no ignorar.

\section{La situación ecuatoriana: problemas, peligros y suge- rencias}

\subsection{La diversidad}

Algunos atribuyen a los antropólogos "militantes" la responsabilidad de haber removido el avispero de la diversidad cultural. "Antes, dicen, vivíamos todos en paz, hasta que a algunos iluminados se les ocurrió introducir ideas pere- 
grinas en la cabeza de los indígenas y ahora no hay quién los aguante". La afirmación es un poco simplista. La diversidad cultural existió siempre en la realidad de los hechos y no es un invento de los antropólogos. Si hubo un tiempo en que una parte de la población aceptaba el sometimiento y la marginación, es algo que hay que lamentar. Ahora esas masas explotadas y silenciosas reclaman un espacio y exigen ser escuchadas: el hecho responde a justicia, lo digan o no los antropólogos. Además es un estereotipo que debe ser revisado, eso de que los indígenas necesitan siempre de alguien que les sugiera lo que deben decir: saben perfectamente cómo hacerlo.

Dicho esto es indispensable añadir de inmediato un corolario: la diversidad existe, pero no hay que exasperarla, una cosa es tomar conciencia y otra es cultivar un resentimiento sempiterno. Vivir llorando los males del pasado es masoquismo puro. Todos los pueblos han sufrido experiencias dolorosas, pero han sobrevivido solo aquellos que no se han replegado sobre sus infortunios. Si la reivindicación de lo propio se traduce en agresividad hacia los demás o menosprecio de sus maneras de ser, entramos ya en una dinámica destructiva $\mathrm{y}$, por ende, inaceptable.

\subsection{El manejo político de los números}

Las organizaciones indígenas, hablando de la consistencia numérica de la población de origen autóctono, manejan un porcentaje que va del 35 al $40 \%$. Ya hemos visto que el dato biológico puede ser este y aun más alto, pero lo que pesa es lo cultural. El origen de uno tiene poco peso si él no se considera indígena, ni quiere serlo, ni desea que lo sean sus hijos y, por esto, los va orientando y educando de cierta manera. La cuestión es menos marginal de lo que parezca a primera vista. En política lo que valen son los votos y estos se cuentan. Si el cálculo del número de posibles sim- 
patizantes es demasiado optimista, es inevitable que las urnas deparen sorpresas desagradables. No se puede hablar a nombre de las mayorías $\mathrm{y}$, peor, querer gobernar como si se las representara, cuando solo un $7 \%$ se considera indígena.

La tentación puede ser entonces la de acudir a otros medios, para medir fuerzas, como los paros y los cortes de carreteras. Pero estos instrumentos se desgastan rápidamente y se ubican fuera del juego democrático, lo que los expone a un alto riesgo de rechazo de parte de la opinión pública. Bolivia enseña. La historia reciente del Ecuador también.

\subsection{Amistades peligrosas}

En política las alianzas son indispensables porque, para alcanzar la eficacia, hay que unir fuerzas. A menudo, estos pactos son tildados despectivamente de "amarres" pero, de hecho, son inevitables. Es muy raro que una agrupación partidista disponga de una mayoría absoluta y, aún en este caso, deberá pactar para mantener la cohesión entre las corrientes internas. El caso más frecuente es que falte cierta cuota de votos para tomar una desición y entonces las organizaciones pequeñas asumen un peso determinante, porque pueden inclinar la balanza a un lado o al otro. Es imaginable la cantidad de presiones que sufren entonces. Las organizaciones indígenas se han encontrado a veces en esta circunstancia y no siempre han sido cuidadosas en escoger a los aliados. Ciertas opciones, que en lo inmediato pueden parecer rentables, en el largo plazo pasan facturas muy caras.

Resultó evidente que, por su capacidad de convocatoria y su eficacia en bloquear las vías, las organizaciones fueran utilizadas en la caída de Jamil Mahuad. Lo mismo sucedió más tarde, cuando los miembros de las comunas 
fueron traídos en buses y camiones a la capital, para apuntalar al gobierno del coronel Gutiérrez, que había perdido el respaldo ciudadano. Los seis meses en que gobernaron juntamente con Sociedad Patriótica han creado al inicio una sensación de euforia, pero les han causado un debilitamiento y pérdida de credibilidad que superarán solamente en años. En el pasado hubo momentos en los que apoyaron protestas de los petroleros, de los maestros, de los empleados del Seguro Social, es decir, causas bastante alejadas de los intereses populares.

Tampoco faltaron coyunturas en las que el apoyo de la opinión pública a las protestas de los indígenas fue evidente y generalizado, como cuando ellos se refugiaron en la Universidad Politécnica Salesiana, durante la presidencia de Gustavo Noboa, para protestar contra el alza del precio del gas. Pero ese éxito generó una excesiva autoconfianza $y$, el patrimonio de simpatía acumulado en años, se dispersó por ciertos desatinos posteriores.

\subsection{Centrarse en lo específico}

Las organizaciones indígenas, en sus comienzos, luchaban por temas muy cercanos a los intereses de las bases: titulación de las tierras, derechos sobre las aguas, educación bilingüe, reconocimiento de las instancias locales. Después se convirtieron en especie de partidos políticos y pagaron un alto precio por la transformación. Para empezar, se fue produciendo un distanciamiento creciente entre las masas y los dirigentes, hasta el punto que estos son percibidos como presencias lejanas y privilegiadas, que manejan el poder con criterios clientelares.

En segundo lugar, los aliados políticos los llevaron a poner en los primeros lugares de la agenda ciertos tópicos, importantes para el país, pero alejados del sentir de la mayoría indígena, como el Plan Colombia, la oposición a la 
dolarización, la base de Manta, TLC, la deuda externa. No se hace país si no se conectan los intereses locales y de grupos con los de la comunidad nacional, pero es verdad también que la gente es más sensible a lo que la toca de cerca. Si se la hace desfilar demasiadas veces detrás de carteles que aluden a temas poco sentidos o cuyo alcance entiende apenas, esa gente acabará cansándose.

\subsection{No desperdiciar las oportunidades}

Hay conquistas que son importantes, pero no definitivas: para que den todo el fruto de que son capaces es indispensable seguir fortaleciéndolas. Me limitaré al ejemplo concreto de la Educación Intercultural Bilingüe. En 1989 fue aprobada por el gobierno de Rodrigo Borja y extendida a todo el país. Se trataba de una excelente oportunidad para crear conciencia en las nuevas generaciones, volverlas a familiarizar con los valores tradicionales, volcar la sabiduría ancestral en los textos, experimentar nuevos métodos de aprendizaje, para que, de esas escuelas, salieran individuos verdaderamente bilingües, orgullosos de su identidad y, al mismo tiempo, abiertos a los desafíos del mundo actual.

No digo que se tratara de una tarea fácil: es complicadísima y encuentra resistencias de todo tipo, especialmente en tiempos de globalización. Tampoco afirmo que nada se haya hecho, pero es indudable que los resultados son modestos. Lo que se ha visto es que el programa se ha politizado de inmediato, tomando la palabra en el peor de sus significados: convertir las estructuras culturales y locales en un área de pillaje, para asegurar puestos, sueldos y ubicación de partidarios o parientes. Las direcciones provinciales se volvieron burocracias paralelas a las de la educación hispana, pesadas y sin creatividad. Hablando más en general, y no solo del caso específico de la Educación Intercultural Bilingüe, es evidente que hay que resistir a la tenta- 
ción de multiplicar y ampliar los frentes, simplemente porque la cooperación internacional no deja faltar los medios económicos. Cuando una iniciativa no se sostiene con el esfuerzo propio, no solamente levanta castillos inconsistentes, sino que acostumbra a la dependencia y a la actitud pedigüeña, que favorecen nuevos formas de coloniaje.

\section{Universidad y minorías}

En todo este proceso de transformación de las luchas y organizaciones indígenas, ¿se puede decir que la universidad haya dado un aporte palpable? La respuesta es: sí.

¿Podía y puede dar más? La respuesta es nuevamente: sí, muchísimo más.

\subsection{Acompañar la reflexión}

El propósito de convertirse en intelectuales orgánicos puede constituir para los universitarios una verdadera tentación: la de tomar partido, sin medir todas las consecuencias. Si definirse significara apoyar a los más débiles, sería sin duda un proyecto loable, pero con frecuencia se trata de algo más concreto y modesto: la alineación con agrupaciones partidistas, cuyas intenciones no son muy claras. El epílogo es fácil de prever: terminar destrozados por mezquinos conflictos de poder. Es evidente también el peligro opuesto, el de opinar al amparo de una campana de vidrio, sin correr riesgos, ni ensuciarse las manos.

Como siempre, existe un camino intermedio. Es la disposición a acompañar discretamente cuando uno es requerido, sin invasiones de campo, sin protagonismos. No solo los indígenas, sino todos los sectores de la sociedad, para áreas específicas, requieren de asesores tanto nacio- 
nales, como extranjeros. Se los llama, se los escucha, se evalúan sus propuestas, pero no se les delega la toma de decisiones. No hay solo el asesoramiento a las organizaciones de tercer y cuarto grado. Puede que acompañar a una comunidad apartada sea menos gratificante, pero tiene igual importancia: organización, salud, educación, desarrollo, derechos humanos. Además, tanto a nivel de base como de cúpulas, el área política es solo una entre las tantas en que se requieren expertos. Se puede ayudar mucho con datos históricos, estadísticos, lingüísticos; con investigaciones sobre mitología, creencias, música, medicina tradicional.

\subsection{Fomentar las investigaciones}

Para ofrecer la información, en los campos arriba mencionados, son indispensables investigaciones realizadas con rigor científico. Hace un cuarto de siglo todos los antropólogos y lingüistas del país formaron un gran frente con las organizaciones indígenas, con el fin de exigir al gobierno de Roldós que rescindiera el contrato con el Instituto Lingüístico de Verano. La primera parte del propósito fue alcanzada: el ILV dejó el país, por lo menos en cuanto institución. Pero nadie se hizo cargo de las tareas de investigación que quedaron pendientes. A pesar de las promesas, las instalaciones de Limoncocha fueron dejadas en el abandono. El Centro Cultural Abya-Yala, fundado en 1975, se dedicó a investigar, documentar y difundir los valores culturales del mundo indígena. En treinta años la mole de material publicado es imponente, pero Abya-Yala no es propiamente una institución universitaria.

Algunos han hecho notar que en sus catálogos aparece un alto porcentaje de autores extranjeros. No se puede negar, pero esto refleja una realidad, no una opción del consejo editorial. La mayoría de estudios monográficos serios 
sobre etnias del país, los que podríamos llamar los textos clásicos, fueron llevados a cabo por no ecuatorianos. En Quito hay dos escuelas de antropología, a las que en los últimos años se ha añadido la oferta de maestrías, de parte de varias universidades. Existe una producción de cierto nivel, pero muchos son estudios de casos muy circunscritos, o investigaciones bibliográficas.

Investigar cuesta y las universidades nacionales no disponen de fondos generosos como muchas extranjeras. Es un problema real. Será por esto que, en este momento, casi las únicas entidades que financian investigaciones son las petroleras. Lo que no deja de constituir cierta paradoja, porque es exactamente su presencia la que acelera el deterioro de las comunidades de la Región Amazónica.

\subsection{Preparan los cuadros}

Otro sector en que las universidades pueden brindar una ayuda valiosa a los pueblos indígenas es el de la formación de cuadros para administrar y dirigir. No se puede ignorar que es el campo en que más han aportado. En su primer momento, la atención se ha centrado, sobre todo, en la educación. Así lo ha hecho la Pontificia Universidad Católica al comienzo de los años 80 y la Salesiana un poco después. En la Universidad Central se han formado también bastantes indígenas. Esto para hablar solo de Quito. A medida que las organizaciones han incursionado en la política, se ha puesto en evidencia que no es suficiente preparar los líderes a través de las Ciencias de la Educación. Se necesitan economistas, administradores, comunicadores, sociólogos, antropólogos.

La Fundación Hans Seidel ha advertido tempranamente esta exigencia y, a través de becas, ha ayudado para que un buen número de indígenas estudiara en diferentes universidades. Es un ejemplo que debe ser imitado, porque 
se trata del mejor servicio que se pueda ofrecer a estos pueblos. Nadie los salvará sino ellos. Juntamente con la autoestima deben adquirir todas las destrezas que les permitan vivir en un mundo complejo y globalizado. El sistema de becas es muy útil para jóvenes que pertenecen a grupos carentes de recursos, pero no es el único y no es suficiente. La necesidad de personas cualificadas es enorme y las universidades no están en condición de becar a todos los candidatos, sin tener en cuenta que la beca-regalo sabe a paternalismo. Hay que estudiar robustos sistemas de créditos: una vez profesionalizados, no les resultará difícil a estos jóvenes indígenas devolver, durante años y en cuotas mensuales, lo que han recibido y así ayudar a otros.

\section{Epílogo}

Después de tantas puntualizaciones, probablemente quede la impresión de que se ha regresado al punto de partida: la diversidad existe, pero ¿qué hacer con ella? Quede bien claro que, en este campo, no se pueden pretender recetas válidas y definitivas para todas las circunstancias: las metas que se alcanzan son equilibrios provisionales y es necesario reconstruirlos permanentemente. Dicho esto, se pueden trazar algunos criterios que ayuden en la búsqueda de pautas de conducta:

1. Hay que evitar las alternativas rígidas: uso exclusivo del idioma propio o uso exclusivo del idioma nacional; asimilación total o independencia política; conservación de la tradición o apertura a la modernización. Si se lo busca, siempre se encuentra un camino intermedio. Generalmente se trata de eliminar la partícula disyuntiva y sustituirla con la coyuntiva.

Se puede conservar la tradición, pero sin volverla una camisa de fuerza; hay que abrirse a la modernización, pero sin echar por la borda todos los valores del pasado; no hay 
que olvidar el idioma del grupo, pero hay que conocer también los idiomas que conectan con áreas más grandes y con el mundo. Es muy útil definir cuidadosamente las fronteras de la cultura a la que uno pertenece, pero sin convertirlas en fronteras políticas: seria puro autolesionismo. En el mundo actual tenemos todos pertenencias plúrimas. Uno puede ser, al mismo tiempo, shuar, ecuatoriano y latinoamericano. Lo uno no excluye lo otro.

2. Vivir juntos, siendo diferentes, no es fácil, pero tampoco imposible: es cuestión de un tipo de educación que sepa ir en contravía de los estereotipos: los costeños son así, los indios son de esta manera, los gringos de esta otra. Desde muy pequeños el ambiente nos inculca prejuicios: son mecanismos sicológicos de defensa de la identidad del grupo, pero hoy es mucho más el daño que causan que las ventajas que brindan. Hemos ilustrado las dificultades que nacen del convivir con la diversidad, presentando el ejemplo de varios países que aún no han encontrado una fórmula aceptable. Existen también ejemplos de logros, como en el caso de Suiza: allí se hablan cuatro idiomas, se siguen varios credos religiosos y conviven tres culturas de raíces históricas diferentes: la alemana, la francesa y la italiana. EI sistema de gobierno es muy descentralizado y el país goza de una paz envidiable. Bélgica es otro ejemplo, aunque un poco más complejo. El Sudáfrica de Nelson Mandela enseña que es posible vencer obstáculos que parecían insuperables.

3. Es importante no confundir conservación de valores y folclor. A veces se lucha y se invierte mucho con el fin de mantener o recuperar tradiciones, pero para uso y consumo del turismo. Es un camino legítimo, pero no tiene nada que ver con el mantenimiento de la identidad. Al contrario, suele ser el camino más directo para vaciarla de todo contenido y volverla una simple cáscara. 
4. Los pueblos indígenas pueden optar por fundirse en la gran masa del mundo mestizo y renunciar a una identidad propia. Esta decisión les toca a ellos tomarla y nadie se lo puede impedir. Pero si, dentro de cierta inevitable integración a las grandes estructuras del país, desean conservar su personalidad étnico-cultural, sepan que esto es posible, pero no recibirán descuentos. En cierto sentido es escoger ir contra corriente y pide un esfuerzo que nadie puede asumir en su lugar. Nunca avanzarán si se limitan a lamentar las desgracias del pasado o a organizar protestas. En una democracia auténtica los únicos privilegiados son aquellos que, por incapacidad física o mental, no pueden valerse por sí solos. No es el caso de los pueblos indios. Un espacio dentro del mundo actual ellos nunca lo recibirán como regalo, sino que deberán conquistarlo. 